\title{
Mechanical and optical effects of elastomer interaction in polypropylene modification: Ethylene-propylene rubber, poly-(ethylene-co-octene) and styrene-butadiene elastomers
}

\author{
C. Grein ${ }^{1,2}$, M. Gahleitner ${ }^{2 *}$, K. Bernreitner ${ }^{2}$ \\ ${ }^{1}$ SABIC Europe, P.O.Box: 5151, 6130 Sittard, The Netherlands \\ ${ }^{2}$ Borealis Polyolefine GmbH, Innovation Headquarters, St. Peterstraße 25, 4021 Linz, Austria
}

Received 9 January 2012; accepted in revised form 12 March 2012

\begin{abstract}
The interaction between binary combinations of three different elastomer classes commonly applied in impact modification of isotactic polypropylene (iPP) was studied. Blends based on a homogeneous ethylene-propylene (EP) random copolymer (EP-RACO) and a heterophasic EP impact copolymer comprising ethylene-propylene rubber (EPR) with different external elastomer types, one homogeneous ethylene-1-octene copolymer (EOC), and two hydrogenated styrenebutadiene-styrene triblock copolymers (SEBS) with different styrene content, were prepared. The phase morphology, mobility as a function of temperature, mechanical and optical properties were studied. Special effects could be achieved for the combination of two different elastomer types. The results clearly demonstrate the possibility to achieve attractive property combinations in ternary systems consisting of a crystalline PP matrix and two different types of elastomer, EPR or EOC on the one hand and SEBS on the other hand. A combination of density matching and compatibilization effects allows reaching good low temperature impact strength together with a transparency close to matrix level when selecting a butadiene-rich SEBS type.
\end{abstract}

Keywords: mechanical properties, polypropylene, elastomer, morphology

\section{Introduction}

Heterophasic polypropylene (PP) copolymers or blends, consisting of a crystalline polypropylene (co)polymer matrix and a largely amorphous elastomeric component, are typically chosen for their high impact strength in numerous applications [1, 2]. When the relation between matrix stiffness and elastomer amount results in a 'stiff' final material (i.e. having a modulus above $800 \mathrm{MPa}$, often going up to more than $1500 \mathrm{MPa}$ ) the target applications mostly are in the injection moulding area, ranging from thin-wall packaging for foodstuff like icecream or dairy products to components for cars and electrical equipment. When matrix crystallinity is reduced by copolymerization and leads together with a high elastomer amount to a 'soft' material (i.e. having typically a modulus below $700 \mathrm{MPa}$, often going down to less than $400 \mathrm{MPa}$ ) the target applications mostly are in the (cast or blown) film area, ranging from flexible lids and stand-up pouches for food packaging to highly specialized and very soft pillow pouches for the medical and pharmaceutical area [3]. A significant widening of the available property range in recent years has allowed PP to substitute other polymer materials both in the stiff area (like polystyrene or polyamide) and in the flexible area (like polyethylene or plasticised poly(vinyl chloride)).

Designing tailored polymer compositions can be challenging since many polymer properties are

\footnotetext{
${ }^{*}$ Corresponding author, e-mail: markus.gahleitner@borealisgroup.com
} (c) BME-PT 
directly or indirectly interrelated. It is, for example, difficult to combine low temperature impact strength and transparency. Because of the density difference between crystalline matrix $\left(900-910 \mathrm{~kg} / \mathrm{m}^{3}\right)$ and rather amorphous elastomer particles (840$880 \mathrm{~kg} / \mathrm{m}^{3}$ ), the latter will act as scattering centres for light if they are big enough. For transparent materials the particles should therefore be as small as possible [4] or closely matched in refractive index (i.e. in density when talking about PP and PE mix). The particle size is, however, directly related to compatibility and viscosity ratio, both in extruder blend systems [5-9] and in reactor-made multiphase copolymers [8-13]. Especially for materials with good flowability elastomer components of very low viscosity are required which necessarily only deliver a very limited contribution to the impact strength [10]. Because of that and due to high nonlinearities in the toughness evolution a combination of different mechanical requirements can be challenging with purely reactor-based solutions $[8,9]$.

One possible solution for combining low temperature impact strength and transparency is the additional application of external elastomer types. High impact strength levels, but normally only limited optical performance can be achieved with ethyleneco-octene or -butene plastomers and elastomers based on polymerisation with single-site catalysts in solution like ENGAGETM from DOW or EXACT ${ }^{\mathrm{TM}}$ from ExxonMobil [14-18] when the densities typically range typically in between 850 and $875 \mathrm{~kg} / \mathrm{m}^{3}$. The comonomer content [15] and the molecular weight [18] of these homogeneous copolymers can be varied in a wide range, allowing applicability in a wide range of stiffness and melt flow rate (MFR), the density difference and 'sharp' interface to the iPP matrix (i.e. without co-crystallization across the phase boundary) are clearly causing light scattering and limiting transparency.

Very good optical performance, but only limited low-temperature impact strength is reached with ethylene-propylene block copolymers of the Vistamaxx $^{\mathrm{TM}}$ type by ExxonMobil due to the excellent compatibility to PP and its copolymers [19, 20], and a density close to $900 \mathrm{~kg} / \mathrm{m}^{3}$. The main reason for the comparably poor impact performance is the relatively high glass transition temperature of these polymers at $\sim 30^{\circ} \mathrm{C}$. Only limited experience exists so far for the use of olefin block copolymers pro- duced with a chain-shuttling catalyst concept [18, $21,22]$, but no particularly advantageous optical performance has been reported.

Finally, styrene-based elastomers of the di- or triblock type have found uses in special areas despite their comparatively higher price [23, 24]. Mostly hydrogenated styrene-butadiene triblock systems are used which can be designed in a wide range of compatibility and viscosity by varying the molecular weight and individual block lengths [25]. Otherwise inaccessible combinations of density and glass transition - e.g. $910 \mathrm{~kg} / \mathrm{m}^{3}$ and $-62^{\circ} \mathrm{C}$ for a styrene content of $30 \mathrm{wt} \%$ - and the good compatibility between the elastomer blocks and iPP allow unique blend properties, especially when targeting soft compositions [26].

In most of the papers cited so far single examples of external elastomer types have been studied in combination with a homogeneous iPP matrix or, in some cases, as compatibilizers between iPP and high density polyethylene (HDPE) [10, 27, 28]. When modifying reactor-based high-impact EP copolymers, the effect of interactions with the internal EPR and PE phases needs to be considered as well. For this purpose, the interaction between binary combinations of three different elastomer classes commonly applied in impact modification of isotactic polypropylene (iPP) was studied.

\section{Experimental work}

Blends based on a homogeneous ethylene-propylene (EP) random copolymer (EP-RACO) and a heterophasic EP impact copolymer comprising ethylene-propylene rubber (EPR) with different external elastomer types, one homogeneous ethylene-1octene copolymer (EOC), and two hydrogenated styrene-butadiene-styrene triblock copolymers (SEBS) with different styrene contents, were prepared and investigated. The following two commercial iPP copolymer grades from Borealis (Austria) were selected as base and matrix materials:

(a) the homogeneous random copolymer (PP-R) RJ370MO having an ethylene content of $3.9 \mathrm{wt} \%$, a density of $900 \mathrm{~kg} / \mathrm{m}^{3}$ and a melt flow rate (MFR acc. ISO $1133,230^{\circ} \mathrm{C} / 2.16 \mathrm{~kg}$ ) of $45 \mathrm{~g} / 10 \mathrm{~min}$, and

(b) the heterophasic impact copolymer (PP-I) Borpact ${ }^{\mathrm{TM}} \mathrm{BC} 918 \mathrm{CF}$ having an ethylene content of $4.8 \mathrm{wt} \%$, an EPR content determined as xylene 
soluble fraction at $+25^{\circ} \mathrm{C}$ of 14 wt. $\%$, a density of $905 \mathrm{~kg} / \mathrm{m}^{3}$ and a MFR of $3,0 \mathrm{~g} / 10 \mathrm{~min}$.

The seemingly high difference in flowability resp. molecular weight between the two base polymers results from the wish to have a comparable matrix viscosity, as the PP-I matrix component (PP homopolymer) has a comparable viscosity to the PP-R $[10,11]$.

As external elastomers, three different types selected from two of the aforementioned classes were selected:

(i) a homogeneous elastomeric ethylene-1-octene copolymer (EOC), Engage 8400 from DOW Chemical (USA) having an octene content of $40 \mathrm{wt} \%$, a density of $870 \mathrm{~kg} / \mathrm{m}^{3}$ and an MFR $\left(190^{\circ} \mathrm{C} / 2.16 \mathrm{~kg}\right)$ of $30 \mathrm{~g} / 10 \mathrm{~min}$,

(ii) a conventional hydrogenated styrene-butadiene-styrene triblock copolymer (SEBS1), Kraton G 1652 from Kraton Inc. (USA) having a high styrene content of $30 \mathrm{wt} \%$, a density of $910 \mathrm{~kg} / \mathrm{m}^{3}$ and an MFR $\left(230^{\circ} \mathrm{C} / 2.16 \mathrm{~kg}\right)$ of $5 \mathrm{~g} / 10 \mathrm{~min}$, and

(iii) another type of SEBS (SEBS2), Kraton G 1657 from Kraton Inc. (USA) having a low styrene content of $13 \mathrm{wt} \%$, a density of $900 \mathrm{~kg} / \mathrm{m}^{3}$ and an MFR $\left(230^{\circ} \mathrm{C} / 2.16 \mathrm{~kg}\right)$ of $22 \mathrm{~g} / 10 \mathrm{~min}$.

All compositions investigated are summarized in Table 1. In addition to the pure base polymers, compositions with one or two types of elastomer at concentrations of $19-20$ and $24-25 \mathrm{wt} \%$ (considering the inherent elastomer content of the PP-I base) were investigated. This means that both binary combinations of iPP matrix with each of the elastomers - EOC, SEBS1, SEBS2 and EPR - as well as ternary combinations including two of these were prepared and tested. All compositions were compounded on a co-rotating twin-screw extruder (Thermo-Prism TSE24, Thermo Fisher Scientific Inc., Germany) of $24 \mathrm{~mm}$ screw diameter and a length to diameter ratio of 48 with a high-intensity mixing screw and a temperature profile at 180 $220^{\circ} \mathrm{C}$ with a throughput of $10 \mathrm{~kg} / \mathrm{h}$ and a screw speed of $50 \mathrm{rpm}$.

For determining the thermo-mechanical performance of the compositions, dynamic-mechanical analysis (DMA) in torsion mode was performed in accordance with ISO 6721 with $50 \times 10 \times 1 \mathrm{~mm}^{3}$ compression moulded samples, as a function of temperature at a test frequency of $1 \mathrm{~Hz}$ with a heating rate of $2 \mathrm{~K} \cdot \mathrm{min}^{-1}$. Measurements were carried out under forced oscillation in a torsion mode $(\varepsilon=0.04 \%)$ with an ARES rheometer (Rheometrics, USA). Temperature dependence of storage modulus $G^{\prime}$ and loss angle tangent $\tan \delta$ were used for evaluation.

The final mechanical and optical properties of the compositions were investigated according to standard procedures on injection moulded specimens prepared in line with EN ISO 1873-2. Standard mechanical data were determined. The parts were not conditioned prior to testing, which was done at least $96 \mathrm{~h}$ after moulding. Charpy notched impact strengths (NIS) were measured on $80 \times 10 \times 4 \mathrm{~mm}^{3}$ specimens at +23 and $-20^{\circ} \mathrm{C}$ according to ISO $179 / 1 \mathrm{eA}$ (test speed of about $3 \mathrm{~m} \cdot \mathrm{s}^{-1}$ ), tensile prop-

Table 1. Investigated compositions and melt flow rate

\begin{tabular}{|c|c|c|c|c|c|c|c|}
\hline \multirow{2}{*}{$\begin{array}{c}\text { Material } \\
\text { number }\end{array}$} & \multicolumn{2}{|c|}{ Base resin } & \multicolumn{4}{|c|}{ Elastomer } & \multirow{2}{*}{\begin{tabular}{|c|} 
MFR \\
$230^{\circ} \mathrm{C} / 2.16 \mathrm{~kg}$ \\
{$[\mathrm{~g} / 10 \mathrm{~min}]$}
\end{tabular}} \\
\hline & $\begin{array}{c}\text { PP-R } \\
{[w t \%]}\end{array}$ & $\begin{array}{c}\text { PP-I } \\
{[w t \%]}\end{array}$ & $\begin{array}{c}\text { EOC } \\
{[w t \%]}\end{array}$ & $\begin{array}{l}\text { SEBS1 } \\
{[\mathrm{wt} \%]}\end{array}$ & $\begin{array}{l}\text { SEBS2 } \\
\text { [wt\%] }\end{array}$ & $\begin{array}{c}\text { total } \\
\text { [wt\%] }\end{array}$ & \\
\hline $\mathrm{M} / 1$ & 100 & & & & & 0 & 40 \\
\hline $\mathrm{M} / 2$ & 80 & & 20 & & & 20 & 39 \\
\hline $\mathrm{M} / 3$ & 80 & & & 20 & & 20 & 16 \\
\hline $\mathrm{M} / 4$ & 80 & & & & 20 & 20 & 22 \\
\hline $\mathrm{M} / 5$ & 80 & & 15 & 5 & & 20 & 33 \\
\hline $\mathrm{M} / 6$ & 80 & & 15 & & 5 & 20 & 34 \\
\hline $\mathrm{M} / 7$ & 75 & & 15 & 10 & & 25 & 29 \\
\hline $\mathrm{M} / 8$ & 75 & & 15 & & 10 & 25 & 29 \\
\hline $\mathrm{M} / 9$ & 75 & & 25 & & & 25 & 32 \\
\hline $\mathrm{M} / 10$ & & 100 & & & & 14 & 3.0 \\
\hline $\mathrm{M} / 11$ & & 95 & 5 & & & 19 & 3.1 \\
\hline $\mathrm{M} / 12$ & & 95 & & 5 & & 19 & 3.2 \\
\hline $\mathrm{M} / 13$ & & 95 & & & 5 & 19 & 3.3 \\
\hline $\mathrm{M} / 14$ & & 90 & 10 & & & 24 & 3.1 \\
\hline $\mathrm{M} / 15$ & & 90 & & 10 & & 24 & 3.4 \\
\hline $\mathrm{M} / 16$ & & 90 & & & 10 & 24 & 4.0 \\
\hline
\end{tabular}




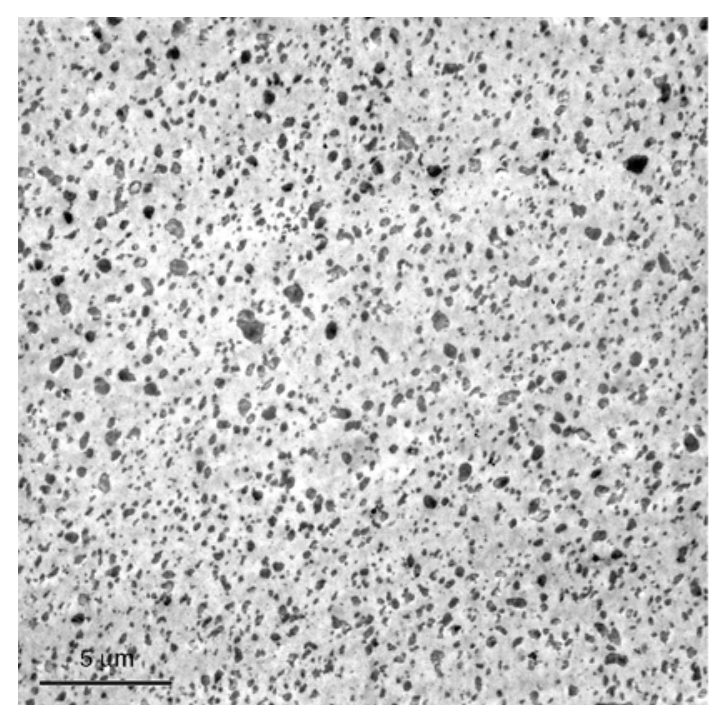

a)

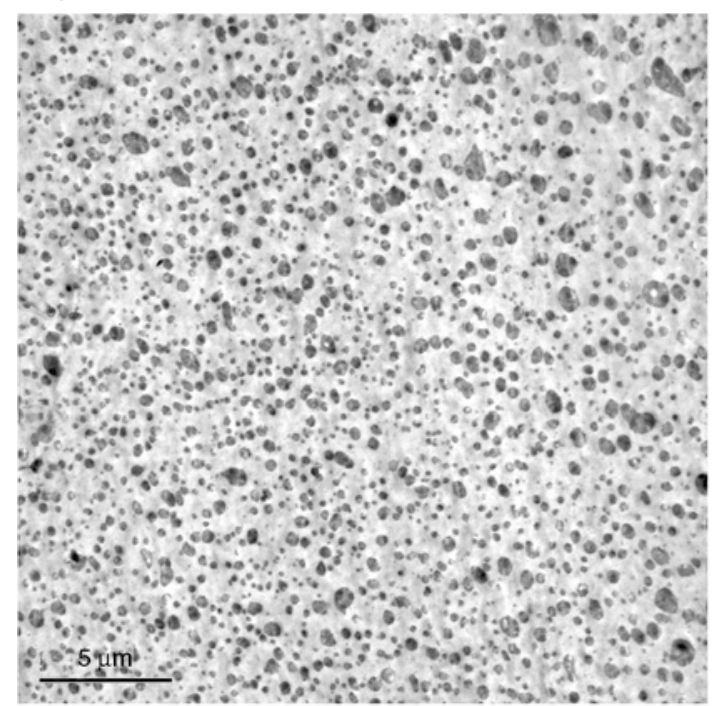

c)

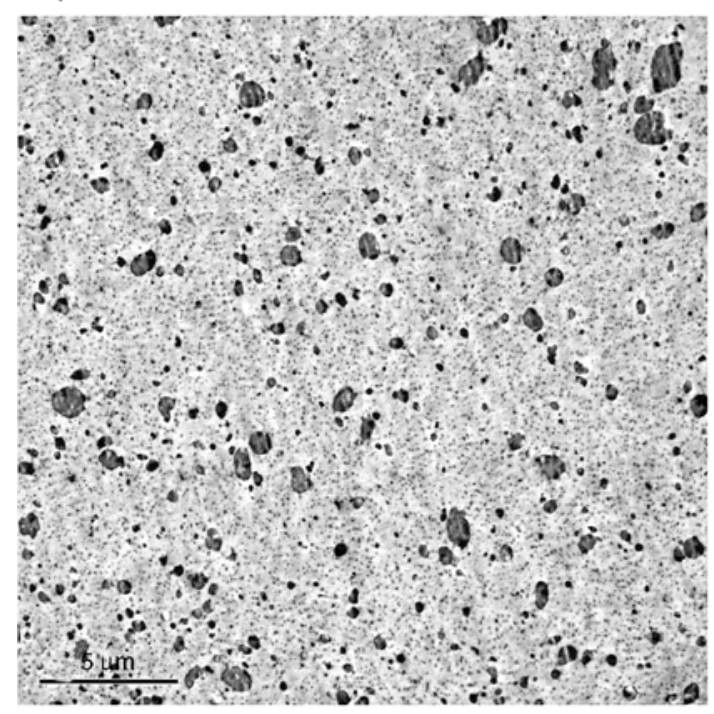

e)

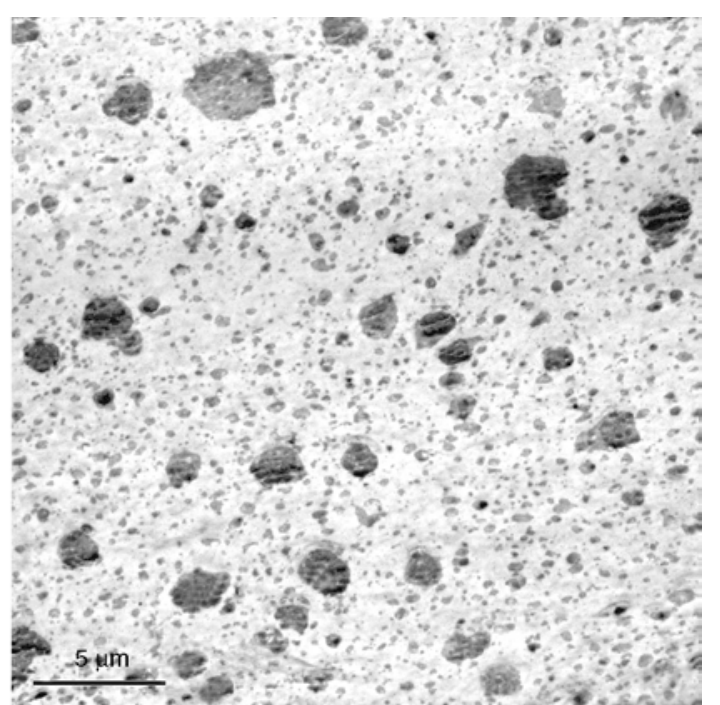

b)

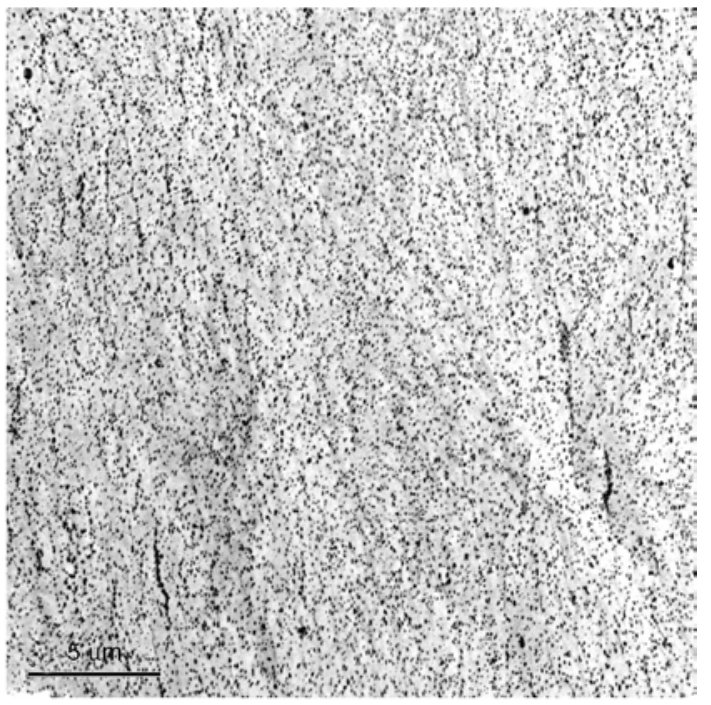

d)

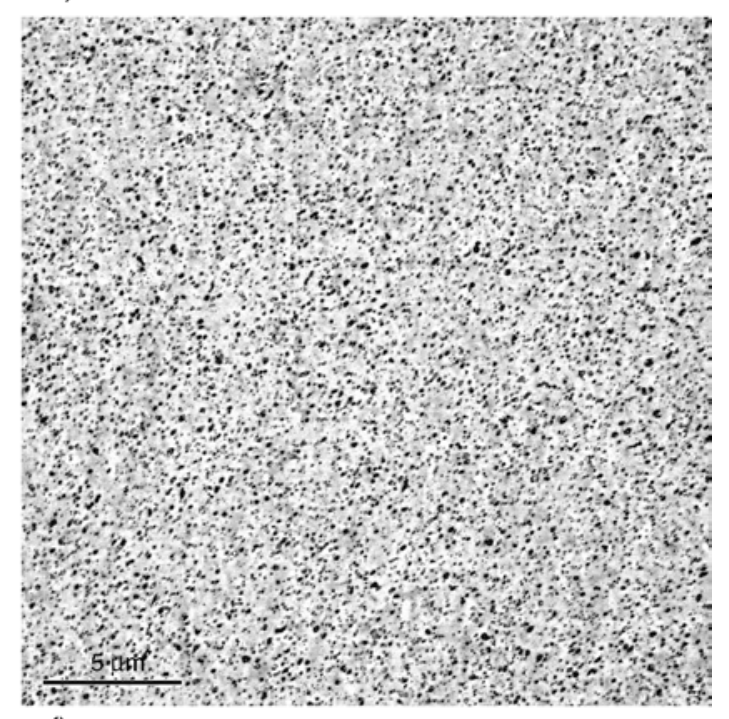

f)

Figure 1. TEM overview images of 6 of the investigated blends (scale bar size $5 \mu \mathrm{m}$ ); (a) M/2 PP-R $+20 \mathrm{wt} \% \mathrm{EOC}$ EG8400, (b) M/5 PP-R + 15 wt $\%$ EOC EG8400 + 5 wt $\%$ SEBS G 1652 (high styrene content), (c) M/6 PP-R + $15 \mathrm{wt} \%$ EOC EG8400 + $5 \mathrm{wt} \%$ SEBS G 1657 (low styrene content), (d) M/10 base polymer PP-I, (e) M/12 PP-I + $5 \mathrm{wt} \%$ SEBS G 1652 (high styrene content), (f) M/13 PP-1 + 5 wt\% SEBS G 1657 (low styrene content) 
erties were recorded on universal ISO dog-bone specimens of $3 \mathrm{~mm}$ thickness at $23^{\circ} \mathrm{C}$ according to ISO $572-2$ at a test speed of $1 \mathrm{~mm} \cdot \mathrm{min}^{-1}$ for the modulus and $50 \mathrm{~mm} \cdot \mathrm{min}^{-1}$ for yield stress and yield strain. The haze, a commonly applied measure for light scattering inverse to transparency, were determined on $60 \times 60 \times 1 \mathrm{~mm}^{3}$ plaques according to ASTM D 1003.

For studying the phase morphology, the samples were also investigated by transmission electron microscopy (TEM) on ultra-microtomed specimens after contrasting with ruthenium tetroxide to allow differentiation between regions of high and low crystallinity [29]. TEM images were recorded on a Tecnai $G^{2} 12$ from FEI (USA), equipped with a CCD camera (Gatan Bioscan, USA) at $100 \mathrm{kV}$ acceleration voltage at the Center for Electron Microscopy Graz, Austria.

\section{Results and discussion}

An overview of all blend morphology types is presented in Figure 1. The first three images present both binary and ternary blend systems based on the homogeneous random copolymer matrix (PP-R) with a clear order of compatibility between the matrix polymer and the three different elastomer types expressed in the resulting particle size. While in all cases an equivalent particle diameter of $3 \mu \mathrm{m}$ is not exceeded, the smallest particles are clearly achieved with the pure EOC elastomer (1a, composition $\mathrm{M} / 2$ ). The ternary compositions, $\mathrm{M} / 5$ and $\mathrm{M} / 6$ are quite different insofar as with the styrene-rich
SEBS type a clearly bimodal particle size distribution is achieved while with the butadiene-rich SEBS the morphology is very similar to the binary reference. A generally better dispersion is achieved in the reactor-based PP/EPR systems like the pure PP-I matrix $\mathrm{M} / 10$. But even here only the butadiene-rich SEBS allows retaining the largely monomodal particle size distribution (M/13), while a similar bimodality with significantly bigger practically pure SEBS particles results from the addition of the styrene-rich type in $\mathrm{M} / 12$.

The mechanical and optical performance of all compositions is summarized in Table 2. As to be expected, the composition-induced differentiation is smallest for the tensile modulus (see Figure 2), where only for the PP-R based blends with higher total elastomer content a certain effect of the styrene content of the SEBS types used can be seen. This is well in line with earlier PP/elastomer blend series where a simple 'mixing rule' behaviour was found for the (tensile, flexural or dynamic) moduli $[4,6,9]$.

Figure 3 demonstrates a significantly stronger differentiation for the impact strength at room temperature, while a look at Table 2 will confirm that quite similar trends are found for the low-temperature impact strength. In the case of the PP-R base, the toughness order for the binary compositions at $20 \mathrm{wt} \%$ elastomer is butadiene-rich SEBS (G1657) $>$ EOC (EG 8400) > styrene-rich SEBS (G1652), but the differentiation is even enhanced for the ternary systems. A closer look at the blend morphology (see Figure 4) and the low temperature mobility

Table 2. Mechanical and optical properties (Tensile test - ISO 527-2, Charpy NIS - ISO 179 1eA, Haze - ASTM D 1003)

\begin{tabular}{|c|c|c|c|c|c|c|c|}
\hline \multirow{2}{*}{$\begin{array}{c}\text { Material } \\
\text { number }\end{array}$} & \multirow{2}{*}{$\begin{array}{c}\text { Elastomer } \\
\text { total } \\
{[w t \%]}\end{array}$} & \multicolumn{3}{|c|}{ Tensile test } & \multicolumn{2}{|c|}{ Charpy NIS } & \multirow{2}{*}{$\begin{array}{c}\text { Haze } \\
1 \mathrm{~mm} \\
{[\%]}\end{array}$} \\
\hline & & $\begin{array}{c}\text { Modulus } \\
\text { [MPa] }\end{array}$ & $\begin{array}{c}\sigma_{\text {yield }} \\
{[\mathbf{M P a}]}\end{array}$ & $\begin{array}{c}\varepsilon_{\text {break }} \\
{[\%]}\end{array}$ & $\begin{array}{c}+23^{\circ} \mathrm{C} \\
{\left[\mathrm{kJ} / \mathrm{m}^{2}\right]}\end{array}$ & $\begin{array}{c}-20^{\circ} \mathrm{C} \\
{\left[\mathrm{kJ} / \mathrm{m}^{2}\right]}\end{array}$ & \\
\hline $\mathrm{M} / 1$ & 0 & 1091 & 28.2 & 487 & 4.4 & 1.0 & 23.4 \\
\hline $\mathrm{M} / 2$ & 20 & 798 & 20,8 & 571 & 19.2 & 1.7 & 26.2 \\
\hline $\mathrm{M} / 3$ & 20 & 769 & 20.4 & 420 & 16.4 & 4.6 & 50.7 \\
\hline $\mathrm{M} / 4$ & 20 & 793 & 20.1 & 439 & 24.4 & 2,7 & 34.7 \\
\hline $\mathrm{M} / 5$ & 20 & 756 & 20.3 & 614 & 9.5 & 2.9 & 33.4 \\
\hline $\mathrm{M} / 6$ & 20 & 771 & 20.0 & 594 & 20.2 & 1.7 & 27.8 \\
\hline $\mathrm{M} / 7$ & 25 & 665 & 18.3 & 674 & 13.1 & 4.0 & 36.2 \\
\hline $\mathrm{M} / 8$ & 25 & 783 & 18.9 & 562 & 31.3 & 2.9 & 22.6 \\
\hline $\mathrm{M} / 9$ & 25 & 791 & 19.2 & 561 & 24.4 & 2.7 & 28.3 \\
\hline $\mathrm{M} / 10$ & 14 & 1460 & 31.3 & 528 & 28.1 & 1.3 & 32.3 \\
\hline $\mathrm{M} / 11$ & 19 & 1416 & 28.3 & 589 & 39,1 & 1.4 & 38.8 \\
\hline $\mathrm{M} / 12$ & 19 & 1396 & 28.5 & 565 & 48.5 & 1.6 & 32.0 \\
\hline $\mathrm{M} / 13$ & 19 & 1420 & 28.0 & 606 & 39,9 & 1.4 & 30.7 \\
\hline $\mathrm{M} / 14$ & 24 & 1322 & 25.8 & 582 & 55.5 & 2.3 & 26.6 \\
\hline $\mathrm{M} / 15$ & 24 & 1305 & 26.3 & 507 & 58.4 & 3.0 & 28.9 \\
\hline $\mathrm{M} / 16$ & 24 & 1303 & 25.2 & 497 & 53.2 & 2.5 & 27.2 \\
\hline
\end{tabular}


(see Figure 5) of some of the compositions, especially the ternary ones, appears required here. The much stronger relaxation strength $(\tan \delta)$ of both SEBS elastomers is obvious in combination with the lower glass transition temperature of the butadiene-rich grade, Kraton G1657. This effect can even still be distinguished in the mixture with the EOC plastomer, as the summary in Table 3 shows. A further look at the DMA traces shows that the temperature dependent mobility of the PP matrix phase is obviously not influenced in any case.

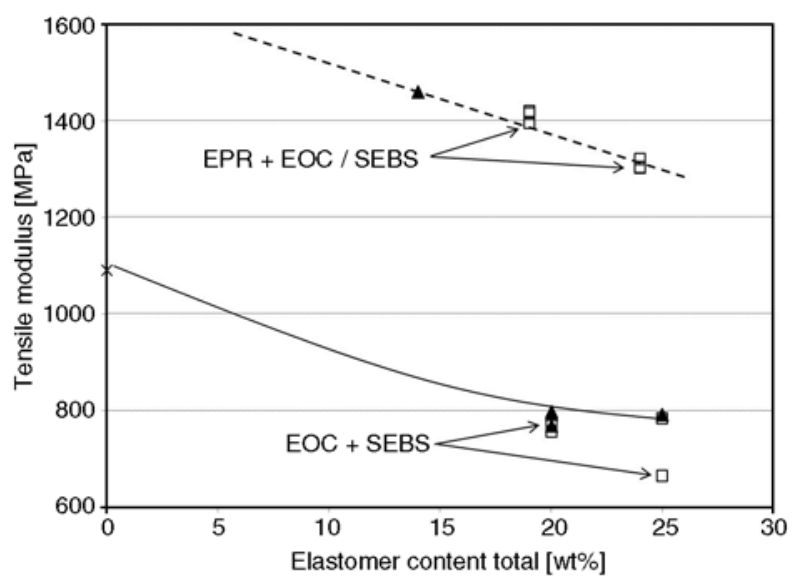

Figure 2. Stiffness effect in binary (full triangles; $M / 2-M / 4$, $\mathrm{M} / 9$ based on PP-R \& M/10 pure PP-I) and ternary (open squares; $\mathrm{M} / 5-\mathrm{M} / 8$ based on PP-R \& $\mathrm{M} / 11-\mathrm{M} / 16$ based on PP-I) PP / elastomer compositions (M/1 pure PP-R - asterisk); trend-lines (continuous for PP-R-base \& dashed for PP-I base) are only indicative

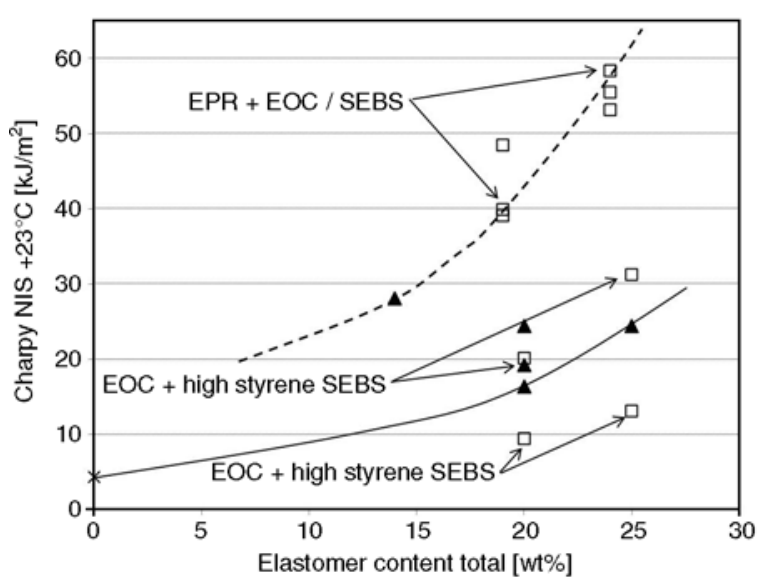

Figure 3. Room temperature impact strength effect in binary (full triangles; $\mathrm{M} / 2-\mathrm{M} / 4, \mathrm{M} / 9$ based on PP-R \& M/10 pure PP-I) and ternary (open squares; $\mathrm{M} / 5-\mathrm{M} / 8$ based on PP-R \& M/11- M/16 based on PP-I) PP / elastomer compositions (M/1 pure PP-R - asterisk); trend-lines (continuous for PP-R-base \& dashed for PP-I base) are only indicative
Table 3. DMA parameters; Glass transition peak temperatures of the elastomer phase $\left(T_{\mathrm{g}, \mathrm{e}}\right)$ and the PP matrix phase $\left(T_{\mathrm{g}, \mathrm{m}}\right)$, and storage modulus at $+23^{\circ} \mathrm{C}$ $\left(G_{23}^{\prime}\right)$

\begin{tabular}{|c|c|c|c|c|}
\hline \multirow{2}{*}{$\begin{array}{c}\text { Material } \\
\text { number } \\
{[-]}\end{array}$} & \multirow{2}{*}{$\begin{array}{c}\text { Elastomer } \\
\text { total } \\
\text { [wt\%] }\end{array}$} & \multicolumn{3}{|c|}{ DMTA parameters } \\
\hline & & $\begin{array}{r}\mathbf{T}_{\mathbf{g , e}} \\
{\left[{ }^{\circ} \mathbf{C}\right]}\end{array}$ & $\begin{array}{l}\mathbf{T}_{\mathbf{g , m}} \\
{\left[{ }^{\circ} \mathbf{C}\right]}\end{array}$ & $\begin{array}{c}\mathbf{G}^{\prime} \\
{[\mathrm{MPa}]}\end{array}$ \\
\hline $\mathrm{M} / 1$ & 0 & - & -4 & 573 \\
\hline$M / 2$ & 20 & -58 & -4 & 465 \\
\hline$M / 3$ & 20 & -62 & -2.8 & 443 \\
\hline $\mathrm{M} / 4$ & 20 & -64 & -2 & 461 \\
\hline $\mathrm{M} / 5$ & 20 & -58 & -4 & 423 \\
\hline $\mathrm{M} / 6$ & 20 & -60 & -1.9 & 413 \\
\hline $\mathrm{M} / 10$ & 14 & -60 & -4 & 580 \\
\hline $\mathrm{M} / 11$ & 19 & -60 & -4 & 515 \\
\hline $\mathrm{M} / 12$ & 19 & -63 & -4 & 508 \\
\hline $\mathrm{M} / 13$ & 19 & -65 & -4 & 497 \\
\hline
\end{tabular}

In addition to this mobility difference, the morphology of the ternary systems shows a certain compatibilizing effect of the EOC plastomer (which itself clearly forms the smallest elastomer particles). A closer look at the particle structure in Figure 4 reveals the fact that the bigger particles for the ternary system $\mathrm{M} / 4$ (the upper part of the bimodal particle size distribution) are the ones rich in (or composed only of) the styrene-rich SEBS which can be identified by the globular styrene domains visible at higher magnifications. For the butadiene-rich SEBS, the compatibilization is more effective and domains of this elastomer can be found only inside an EOC plastomer cover.

This differentiation in terms of impact strength is significantly reduced for the PP-I based blends (see again Figure 2), while the overall toughness level is enhanced especially at room temperature. The high degree of phase compatibility for the selected polymer type results in a relatively high glass transition temperature of part of the reactor-made EPR phase (see Figure 5 and Table 3). This can however be compensated easily by an external elastomer using the compatibilizing effect of this component, as the ternary systems M/11 to M/16 show. Especially the butadiene-rich SEBS type applied for M/13 leaves the particle size of the PP-I base practically unchanged as a comparison between Figures $4 c$ and $4 \mathrm{~d}$ demonstrates.

While it is certainly an important factor for the impact properties of the respective systems, the optical performance is even more affected by the particle size (see Table 2 and Figure 6). If the positive 


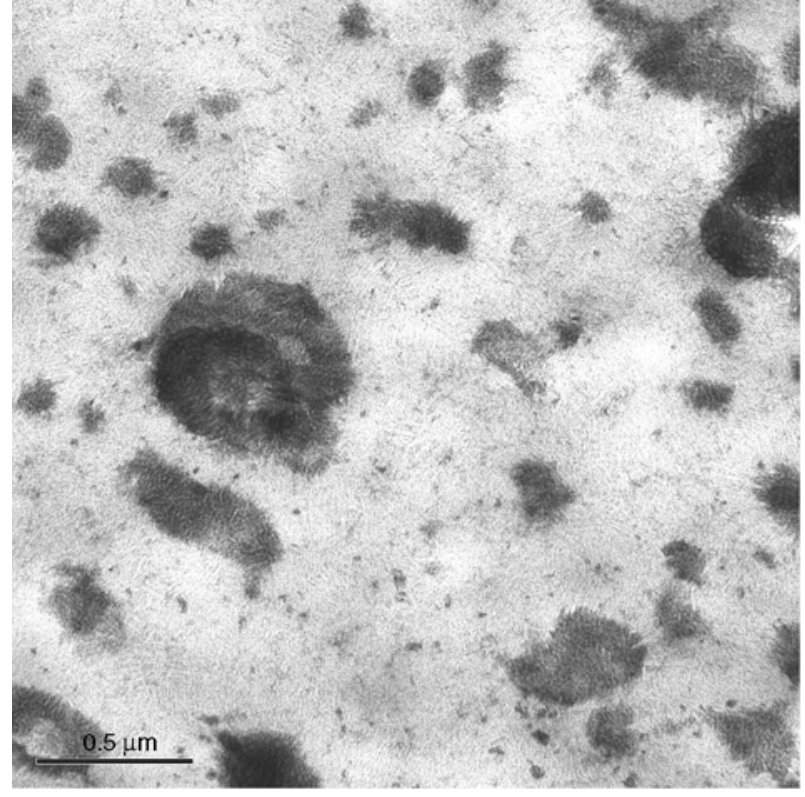

a)

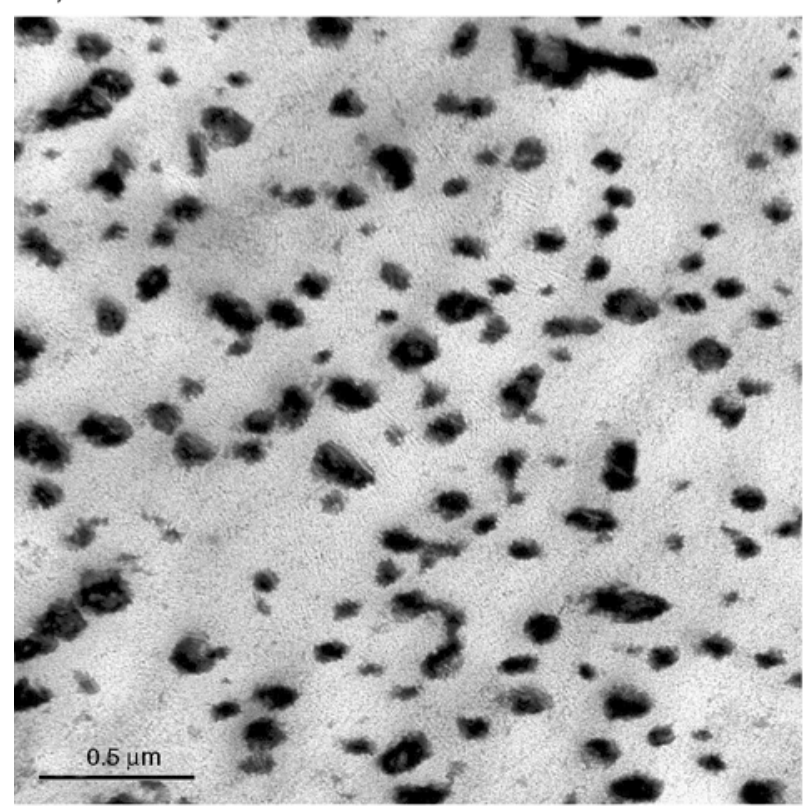

c)

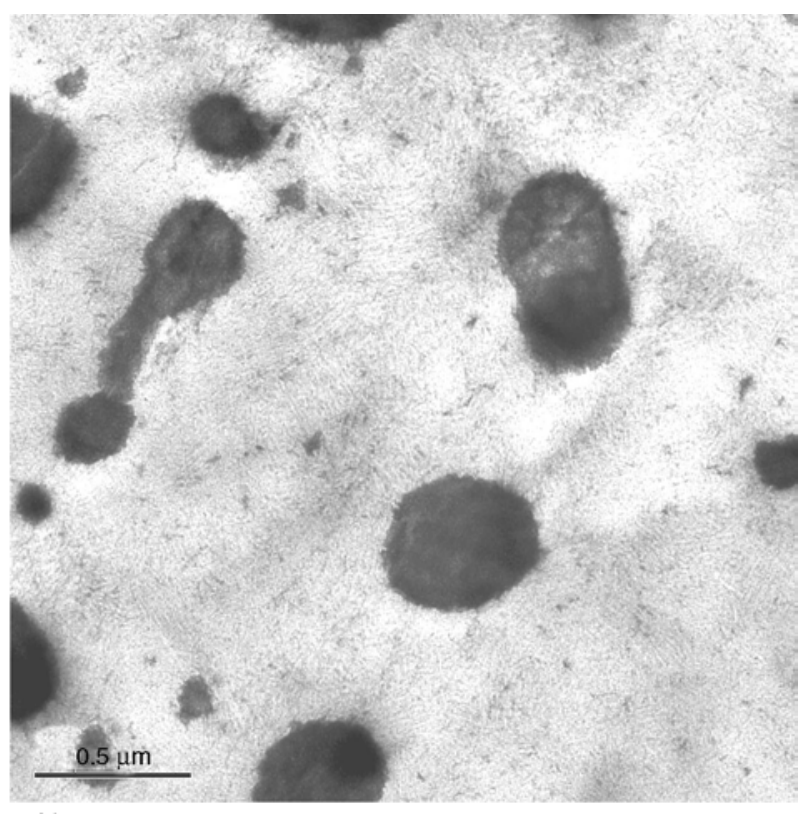

b)

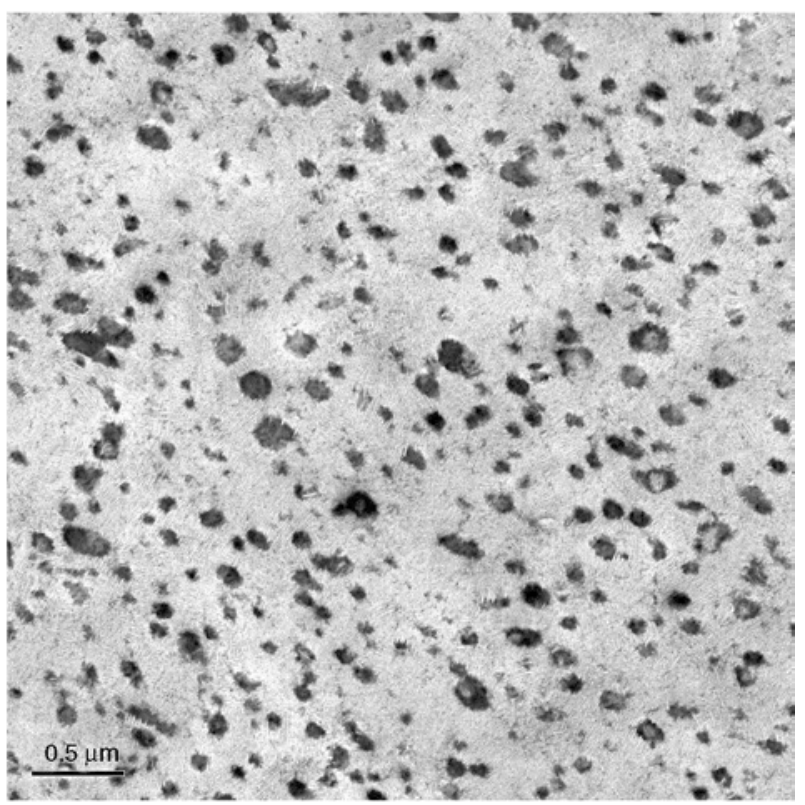

d)

Figure 4. TEM detail images of 4 of the investigated blends (scale bar size $0,5 \mu \mathrm{m}$ ); (a) M/4 PP-R +20 wt $\%$ SEBS G 1652 (high styrene content), (b) M/5 PP-R + $15 \mathrm{wt} \%$ EOC EG8400 + $5 \mathrm{wt} \%$ SEBS G 1652 (high styrene content), (c) M/10 base polymer PP-I, (d) M/13 PP-1 + 5 wt $\%$ SEBS G 1657 (low styrene content)

effect of combining the two elastomers in $\mathrm{M} / 6$ on impact strength is already interesting, the respective effect on transparency improvement (i.e. haze reduction) is outstanding, as the level of the base polymer is eve exceeded here. As the particle size difference is not that big, one may assume that the refractive index of the elastomer mixture plays an important role, as already postulated before [24, 25]. A look at the detail morphology in Figure 4 further shows the change in interfacial structure between the binary
$(\mathrm{M} / 4)$ and ternary $(\mathrm{M} / 5)$ which also may contribute to less light scattering.

The fact that this adjustment in terms of density resp. refractive index can even be used for improving the optical performance of a reactor-based PP/ EPR system is even more interesting for practical applications. Again, the differentiation is reduced by the compatibilizing effect of the reactor-made EPR phase, but the butadiene-rich SEBS type still delivers a slightly better performance. 


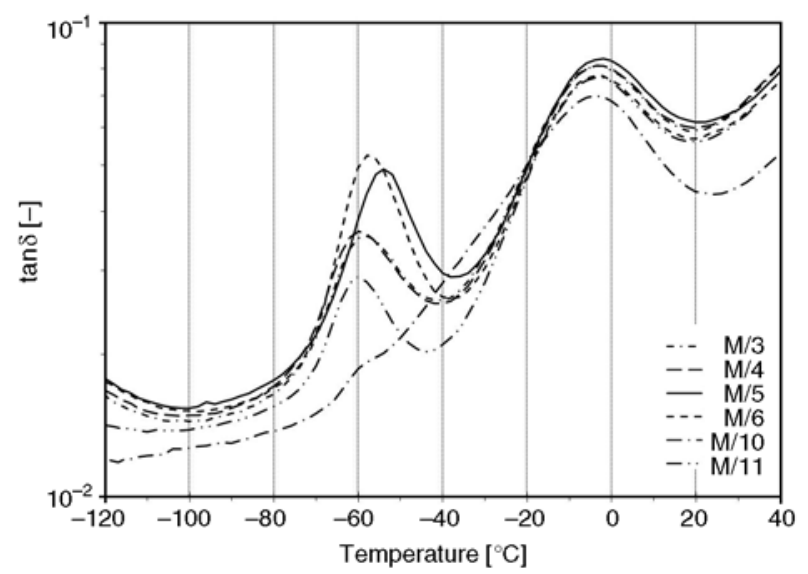

Figure 5. Loss tangent curves in the elastomer and matrix glass transition region $\left(T_{\mathrm{g}, \mathrm{e}}\right.$ and $\left.T_{\mathrm{g}, \mathrm{m}}\right)$ for 6 of the investigated blends (M/3 to $\mathrm{M} / 6$ based on PP-R; M/10 pure PP-I; M/11 PP-I + EOC)

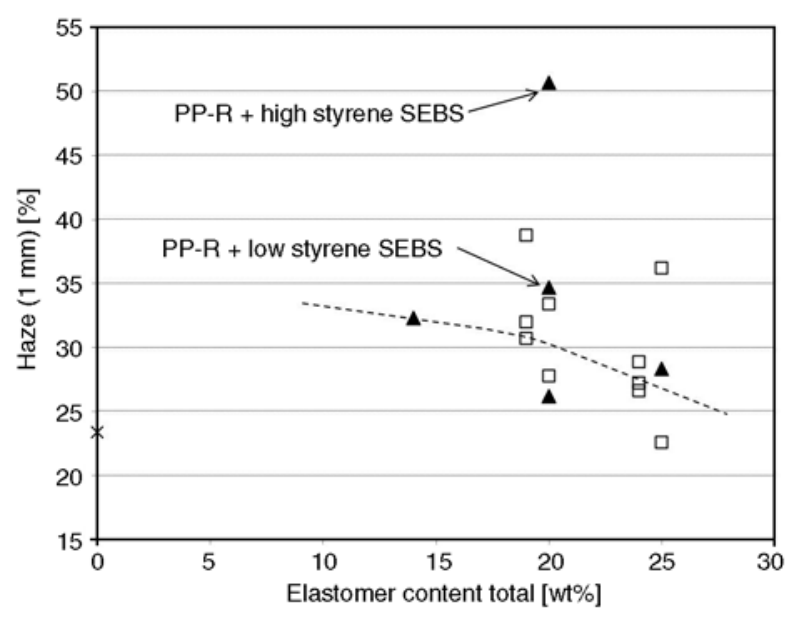

Figure 6. Haze effect in binary (full triangles; $M / 2-\mathrm{M} / 4$, M/9 based on PP-R \& M/10 pure PP-I) and ternary (open squares; $\mathrm{M} / 5-\mathrm{M} / 8$ based on PP-R \& $\mathrm{M} / 11-\mathrm{M} / 16$ based on PP-I) PP / elastomer compositions (M/1 pure PP-R - asterisk); trend-lines (continuous for PP-R-base \& dashed for PP-I base) are only indicative

\section{Conclusions}

The investigated model blend series clearly demonstrates the possibility to achieve attractive property combinations in ternary systems consisting of a crystalline PP matrix and two different types of elastomer, EOC and SEBS or (reactor-made) EPR and SEBS. A combination of density matching and compatibilization effects allows combining good low temperature impact strength and a transparency close to matrix level. When selecting a butadiene-rich SEBS type, the lower glass transition temperature of this elastomer possibly plays an additional role.
In any case, modifications based on a multi-phase impact copolymer deliver a better balance of mechanical and optical properties.

These results give a clear guidance for the development of advanced impact copolymer compositions based on multiphase reactor grades. A combination of density matching and compatibilization effects allows combining good low temperature impact strength and a transparency close to matrix level when selecting a butadiene-rich SEBS type.

\section{References}

[1] Karger-Kocsis J.: Polypropylene: Structure, blends and composites; Vol. 2 - Copolymers and blends. Chapman and Hall, London (1995).

[2] Pasquini N.: Polypropylene handbook. Hanser, Munich (2005).

[3] Schwager H.: PP Reactor blends. in 'Polypropylene '92 World Congress, Zürich, Switzerland' II/4.1II/4.18 (1992).

[4] Coppola F., Greco R., Martuscelli E., Kammer H. W., Kummerlowe C.: Mechanical properties and morphology of isotactic polypropylene/ethylene-propylene copolymer blends. Polymer, 28, 47-56 (1987).

DOI: $10.1016 / 0032-3861(87) 90317-X$

[5] Li L., Chen L., Bruin P., Winnik M. A.: Morphology evolution and location of ethylene-propylene copolymer in annealed polyethylene/polypropylene blends. Journal of Polymer Science Part B: Polymer Physics, 35, 979-991 (1997).

DOI: 10.1002/(SICI)1099-0488(19970430)35:6<979:: AID-POLB12>3.0.CO;2-C

[6] Gahleitner M., Hauer A., Bernreitner K., Ingolic E.: PP-based model compounds as tools for the development of high-impactethylene-propylene copolymers. International Polymer Processing, 17, 318-324 (2002).

[7] Kontopoulou M., Wang W., Gopakumar T. G., Cheung C.: Effect of composition and comonomer type on the rheology, morphology and properties of ethylene- $\alpha$ olefin copolymer/polypropylene blends. Polymer, 44, 7495-7504 (2003).

DOI: $10.1016 /$ j.polymer.2003.08.043

[8] Hayashi K., Morioka T., Toki S.: Microdeformation mechanisms in propylene-ethylene block copolymer. Journal of Applied Polymer Science, 48, 411-418 (1993).

DOI: $10.1002 /$ app.1993.070480305

[9] Grellmann W., Seidler S., Jung K., Kotter I.: Crackresistance behavior of polypropylene copolymers. Journal of Applied Polymer Science, 79, 2317-2325 (2001).

DOI: $10.1002 / 1097-4628(20010328) 79: 13<2317::$ AIDAPP1039>3.0.CO;2-N 
[10] Grein C., Bernreitner K., Hauer A., Gahleitner M., Neiß1 W.: Impact modified isotatic polypropylene with controlled rubber intrinsic viscosities: Some new aspects about morphology and fracture. Journal of Applied Polymer Science, 87, 1702-1712 (2003).

DOI: $10.1002 /$ app.11696

[11] Grein C., Gahleitner M., Knogler B., Nestelberger S.: Melt viscosity effects in ethylene-propylene copolymers. Rheologica Acta, 46, 1083-1089 (2007).

DOI: $10.1007 / \mathrm{s} 00397-007-0200-0$

[12] De La Torre V., Rodríguez Fris J. A., Failla M. D., Quinzani L. M.: Effect of melt annealing on the phase structure and rheological behavior of propylene-ethylene copolymers. Polymer Engineering and Science, 47, 912-921 (2007).

DOI: $10.1002 /$ pen.20775

[13] Zhang C., Shangguan Y., Chen R., Wu Y., Chen F., Zheng Q., Hu G.: Morphology, microstructure and compatibility of impact polypropylene copolymer. Polymer, 51, 4969-4977 (2010).

DOI: 10.1016/j.polymer.2010.08.021

[14] Yu T. C.: Mentallocane plastomer modification of polypropylenes. Polymer Engineering and Science, 41, 656-671 (2001). DOI: $10.1002 /$ pen.10761

[15] Lee H-Y., Kim D. H., Son Y.: Effect of octene content in poly(ethylene-co-1-octene) on the properties of poly(propylene)/poly(ethylene-co-1-octene) blends. Journal of Applied Polymer Science, 103, 1133-1139 (2007).

DOI: $10.1002 / a p p .24644$

[16] Tortorella N., Beatty C. L.: Morphology and crystalline properties of impact-modified polypropylene blends. Polymer Engineering and Science, 48, 14761486 (2008). DOI: $10.1002 /$ pen. 21102

[17] Svoboda P., Theravalappil R., Svobodova D., Mokrejs P., Kolomaznik K., Mori K., Ougizawa T., Inoue T.: Elastic properties of polypropylene/ethylene-octene copolymer blends. Polymer Testing, 29, 742-748 (2010).

DOI: 10.1016/j.polymertesting.2010.05.014

[18] Liu G., Zhang X., Liu C., Chen H., Walton K., Wang D.: Morphology and mechanical properties of binary blends of polypropylene with statistical and block ethylene-octene copolymers. Journal of Applied Polymer Science, 119, 3591-3597 (2011).

DOI: $10.1002 / a p p .33035$

[19] Tsou A. H., Lyon M. K., Chapman B. R., Datta S.: Elastic properties of cast films from propylene elastomers. Journal of Applied Polymer Science, 107, 1362-1372 (2008).

DOI: $10.1002 / a p p .27184$
[20] Chen X-H., Ma G-Q., Li J-Q., Jiang S-C., Yuan X-B., Sheng J.: Study on morphology evolution and fractal character of the miscible blend between isotactic polypropylene and copolymer of ethylene and propylene. Polymer, 50, 3347-3360 (2009).

DOI: $10.1016 /$ j.polymer.2009.04.069

[21] Arriola D. J., Carnahan E. M., Hustad P. D., Kuhlman R. L., Wenzel T. T.: Catalytic production of olefin block copolymers via chain shuttling polymerization. Science, 312, 714-719 (2006).

DOI: $10.1126 /$ science. 1125268

[22] Jin J., Zhao C., Du J., Han C. C.: The possible scalability of mesophase separation on macrophase separation and crystallization of iPP/OBC blends. Macromolecules, 44, 4326-4334 (2011). DOI: $10.1021 / \mathrm{ma} 200194 \mathrm{c}$

[23] Setz S., Stricker F., Kressler J., Duschek T., Mühlhaupt R.: Morphology and mechanical properties of blends of isotactic or syndiotactic polypropylene with SEBS block copolymers. Journal of Applied Polymer Science, 59, 1117-1128 (1996).

DOI: 10.1002/(SICI)1097-4628(19960214)59:7<1117::

$$
\text { AID-APP8>3.0.CO;2-H }
$$

[24] Yang H., Hansen D., Sothwick J.: Low temperature impact modifier for clear polypropylene applications. in 'Proceedings of SPE ANTEC 2006, Charolette, USA' 1766-1770 (2006).

[25] Nobuyuki T., Kazuhisa K., Yukiko N., Masashi S., Motokazu T., Iwakazu H.: Miscibility and properties in the blends of polypropylene with hydrogenated polystyrene-block-polybutadiene-block-polystyrene (SEBS) (in Japanese). Journal of the Society of Rubber Industry, Japan, 75, 530-534 (2002).

[26] Matsuda Y., Hara M., Mano T., Okamoto K., Ishikawa M.: The effect of the volume fraction of dispersed phase on toughness of injection molded polypropylene blended with SEBS, SEPS, and SEP. Polymer Engineering and Science, 95, 1630-1638 (2005).

DOI: $10.1002 /$ pen.20298

[27] Lin Y., Yakovleva V., Chen H., Hiltner A., Baer E.: Comparison of olefin copolymers as compatibilizers for polypropylene and high-density polyethylene. Journal of Applied Polymer Science, 113, 1945-1952 (2009).

DOI: 10.1002/app.30190

[28] Lin Y., Marchand G. R., Hiltner A., Baer E.: Adhesion of olefin block copolymers to polypropylene and high density polyethylene and their effectiveness as compatibilizers in blends. Polymer, 52, 1635-1644 (2011). DOI: 10.1016/j.polymer.2011.02.012

[29] Poelt P., Ingolic E., Gahleitner M., Bernreitner K., Geymayer W.: Characterization of modified polypropylene by scanning electron microscopy. Journal of Applied Polymer Science, 78, 1152-1161 (2000). DOI: 10.1002/1097-4628(20001031)78:5<1152::AIDAPP250>3.0.CO;2-7 